\title{
A CONTROLADORIA COMO FERRAMENTA DE APOIO AS ESTRATÉGIAS COMPETITIVAS: ESTUDO DE CASO NUMA EMPRESA DE TELEFONIA MÓVEL
}

\author{
Sandra Maria dos Santos ${ }^{1}$ \\ Francisco de Assis Soares ${ }^{2}$ \\ Carlos Alberto Correia Lima Junior 3 \\ José Nelson Barbosa Tenório 4
}

\begin{abstract}
Resumo: Este artigo tem como intuito investigar o papel da Controladoria no apoio às estratégias competitivas de uma empresa brasileira de telefonia móvel. Essa indústria se apresenta como um das mais dinâmicas da economia nacional e mundial, possuindo assim, potencial para disseminar novas práticas de gestão que se mostrem úteis na resolução dos problemas empresariais. Realizou-se uma pesquisa de campo, envolvendo entrevistas com dirigentes dos setores de controladoria e executivos ligados à organização. Os resultados evidenciam que as informações do setor de controladoria possibilitam o conhecimento do mercado, de forma a enfrentar a concorrência. $O$ entendimento que os gestores possuem da indústria em que atuam é que essa é atrativa, sendo que a principal ameaça à competitividade da organização no mercado é o grau de rivalidade dos concorrentes.
\end{abstract}

Palavras-chave: Telefonia Móvel. Controladoria. Competitividade.

\section{INTRODUÇÃO}

O ambiente empresarial atual apresenta-se muito seletivo e sujeito a fortes pressões vindas de clientes, fornecedores, concorrentes, governos, sociedade, etc.. Atuando nesse ambiente exigente, os gestores buscam guias para suas ações que permitam conduzir com mais eficiência as organizações pelas quais são responsáveis. A busca por métodos que permitam uma condução mais efetiva dos negócios tem sido o objeto de estudo das ciências administrativas, desde o seu início.

As empresas operadoras de telecomunicações no Brasil podem ser analisadas conforme três momentos distintos: anterior ao Sistema Telebrás, com o Sistema e posterior ao sistema.

a) Momento anterior ao Sistema Telebrás: o processo de telecomunicações no Brasil era um monopólio regulado, explorado principalmente por empresas estrangeiras sendo que as empresas desse segmento conviviam num ambiente de diferentes padrões de comunicação, sem uma visão sistêmica, desfavorecendo uma integração maior entre as regiões do país.

b) Momento do Sistema Telebrás: continuou prevalecendo o monopólio, porém quase que de totalidade estatal. Nesse período as telecomunicações brasileiras tomaram um grande impulso. Havia um sistema de fato, com todas as empresas integradas e falando entre si. Entretanto, 0 fato de ser estatal significava submissão aos controles políticos,

\footnotetext{
1 UFCE, cidade, Ceará. E-mail: smsantos@ufc.br.

2 UFCE, cidade, Ceará. E-mail: soares@ufc.br.

3 UFCE, cidade, Ceará. E-mail: cazaalberto@ terra.com.br.

4 UFPE, Pernambuco, Recife. E-mail: nelson27@ufpe.br.
} 
orçamentários e legais do governo, o que restringiu a capacidade de investimento na expansão da capacidade do sistema, tendo em vista a baixa possibilidade de investimento do Brasil.

c) Momento posterior ao Sistema Telebrás: é o atual momento, o das empresas privatizadas. As características deste momento serão discutidas na presente seção.

O movimento mundial a favor das privatizações começou a partir da década de 80 , tendo como principais representantes Estados Unidos e Inglaterra. Esses países também são considerados responsáveis pela propagação das idéias privatizantes nos países periféricos, tendo em vista que na União Européia, devido às barreiras protecionistas, essa prática era dificultada (LEAL, 2005). Segundo a autora, embora tenham acontecido no mesmo período, as causas das privatizações nas diferentes regiões do mundo são distintas, destacando que, na América Latina, elas advêm da crise fiscal e da dívida externa. No Brasil, a idéia de privatização das empresas operadoras de telecomunicações foi resultado de um processo lento e gradual que se iniciou por volta de 1986.

Conforme Biondi (1999, p.60) "a venda das estatais, segundo o governo, serviria para atrair dólares, reduzindo a dívida do Brasil com o resto do mundo". Ainda conforme o autor, "o dinheiro arrecadado com a venda serviria, ainda, segundo o governo, para reduzir também a dívida interna, isto é, aqui dentro do país, do governo federal e dos estados". (BIONDI, 1999, p.6). Também de acordo com 0 autor, essa expectativa desvaneceu-se tão logo aconteceram as privatizações, pois o governo assumiu dívidas desnecessárias com a venda das estatais, o que contribuiu para 0 aumento da dívida interna e as empresas que compraram as estatais, tanto as multinacionais quanto as brasileiras não usaram capital próprio, mas sim tomaram empréstimos do governo e fora do país para fechar seus negócios o que contribuiu para o aumento da dívida externa do Brasil.

Durante o governo do Presidente Fernando Henrique Cardoso o país retomou as bases do projeto de privatizações preconizado por Collor e reafirmou o projeto de desestatização.

Com a promulgação da Lei Geral de Telecomunicações, em 17 de julho de 1997, documento que substituiu o Código Brasileiro de Telecomunicações (com exceção do setor de radiodifusão), 0 governo instituiu um órgão regulador (ANATEL-Agência Nacional de Telecomunicações), estabeleceu regras de privatização do Sistema Telebrás e condições de atuação das empresas privadas nacionais e estrangeiras no mercado brasileiro de telecomunicações que passaram a contar, a partir de 1988, com poucas restrições e submetidas a algumas obrigações como interconexão de redes e compromisso com a universalização, por tempo determinado. (BRASIL, 2005b)

O papel da Agência Nacional de Telecomunicações, órgão fiscalizador, passou a ser, então, fundamental para conduzir o processo de desestatização e garantir a regulamentação do setor sob os preceitos da Lei Geral, sobretudo porque passou a substituir o Ministério das Comunicações em muitas tarefas e responsabilidades, como a de arbitrar as funções e atividades do atores que participam do setor.

Além de assegurar a competitividade no mercado de telecomunicações, tão reivindicada pelos grandes usuários, 0 aspecto fundamental da reforma no modelo institucional dessa área no Brasil foi o desmembramento do Sistema Telebrás em três holdings regionais, mais a Embratel, privatizada isoladamente e a criação de oito operadoras de telefonia móvel que atuariam em uma banda de freqüência conhecida como banda $A$. Tal fato se deu a partir da quebra constitucional do monopólio estatal no setor, durante o governo de Fernando Henrique Cardoso.

O modelo, que passou do monopólio estatal para o duopólio privado sofreu alterações por ocasião dos leilões das bandas C, D e E, que tinham o objetivo de introduzir novos competidores, melhorando a qualidade dos serviços e aumentando 0 acirramento da competição por tarifas mais atraentes ao consumidor.

Com efeito, as empresas de telecomunicações do Brasil que prestam serviços de telefonia fixa passaram a ser divididas conforme mostrado no quadro 1. 


\begin{tabular}{|c|c|c|c|c|}
\hline Região & Estados que atende & Empresas derivadas do leilão & $\begin{array}{l}\text { Empresa concessionária } \\
\text { independente }\end{array}$ & Empresa espelho \\
\hline \multirow{16}{*}{ Região I } & Minas Gerais & \multirow{16}{*}{$\begin{array}{c}\text { Tele Norte Leste Participações } \\
\text { S/A (Telemar) }\end{array}$} & \multirow{16}{*}{ CTBC Telecom } & \multirow{16}{*}{$\begin{array}{c}\text { Canbra S/A - Mirror } \\
\text { S/A - Vesper S/A }\end{array}$} \\
\hline & Rio de Janeiro & & & \\
\hline & Espírito Santo & & & \\
\hline & Bahia & & & \\
\hline & Sergipe & & & \\
\hline & Alagoas & & & \\
\hline & Pernambuco & & & \\
\hline & Paraíba & & & \\
\hline & Rio Grande do Norte & & & \\
\hline & Ceará & & & \\
\hline & Piaú́ & & & \\
\hline & Maranhão & & & \\
\hline & Pará & & & \\
\hline & Amapá & & & \\
\hline & Roraima & & & \\
\hline & Amazonas & & & \\
\hline \multirow{10}{*}{ Região II } & Rio Grande do Sul & \multirow{10}{*}{$\begin{array}{l}\text { Tele Centro Sul Participações } \\
\text { S/A (Brasil Telecom) }\end{array}$} & \multirow{10}{*}{$\begin{array}{c}\text { Sercontel } \\
\text { CTBC Telecom } \\
\text { CRT }\end{array}$} & \multirow{10}{*}{$\begin{array}{l}\text { Global Village } \\
\text { Telecom Ltda. }\end{array}$} \\
\hline & Santa Catarina & & & \\
\hline & Paraná & & & \\
\hline & Mato Grosso do Sul & & & \\
\hline & Mato Grosso & & & \\
\hline & Rondônia & & & \\
\hline & Acre & & & \\
\hline & Tocantins & & & \\
\hline & Goiás & & & \\
\hline & \begin{tabular}{|l|} 
Distrito Federal \\
\end{tabular} & & & \\
\hline Região III & São Paulo & $\begin{array}{l}\text { Telesp Participações S/A } \\
\text { (Telefônica) }\end{array}$ & $\begin{array}{c}\text { Ceterp } \\
\text { CTBC Telecom }\end{array}$ & $\begin{array}{l}\text { Megatel do Brasil - } \\
\text { Vesper S/A }\end{array}$ \\
\hline & & & & Bonari Holding Ltda. \\
\hline Região IV & Todo o país & Embratel Participações S/A & & (Intelig \\
\hline & & & & Telecomunicações) \\
\hline
\end{tabular}

\section{Quadro 1 - Empresas brasileiras operadoras de telefonia fixa}

Fonte: Brasil (2000).

Atualmente a concorrência entre as operadoras encontra-se bastante acirrada. Conforme dados divulgados no site da Anatel, a participação de mercado das operadoras no mês de maio de 2005 é demonstrada na tabela 1.

TABELA 1: Participação de Mercado das Operadoras de Telefonia Móvel no Brasil (mai/2005).

\begin{tabular}{lr}
\hline & Operadora \\
\hline Vivo & 38,18 \\
Tim & 21,70 \\
Claro & 21,46 \\
Oi & 10,64 \\
Telemig/Amazonia & 5,65 \\
BrT GSM & 1,80 \\
CTBC & 0,46 \\
Sercomtel & 0,11 \\
TOTAL & 100,00 \\
\hline
\end{tabular}

Fonte: www.teleco.com.br 
Em relação às exigências do órgão regulador, ANATEL, existe uma cobrança que se reflete em índices de atendimento de metas. Os itens cobrados pelo órgão serão explicitados na seção do estudo de caso. Na tabela 2, estão contemplados os índices das metas estabelecidas pela agência reguladora que foram atingidos de forma global.

Tabela 2: Desempenho das Operadoras (mai/2005).

\begin{tabular}{lrr}
\hline \multicolumn{1}{c}{ Operadora } & Metas de Qualidade atendidas* & Reclamações por 1000 celulares na Anatel \\
\hline Triângulo Cel.(CTBC) & 100,00 & 0,253 \\
Oi & 81,80 & 0,273 \\
Tim & 83,00 & 0,525 \\
Vivo & 83,40 & 0,305 \\
Sercomtel & 81,80 & 0,106 \\
Telemig & 72,70 & $0,157^{* *}$ \\
Claro & 72,70 & 0,515 \\
Amaz & 68,20 & $* *$ \\
BrT GSM & & 1,721 \\
\hline
\end{tabular}

Fonte: www.teleco.com.br

* \% de metas de qualidade atendidas em relação ao todal de metas das operadoras do grupo.

** Telemig e Amazônia Celular.

\section{REVISÃO BIBLIOGRÁFICA}

\subsection{CONTROLADORIA ESTRATÉGICA}

Conforme Figueiredo (1997) existem duas abordagens com relação à profundidade da responsabilidade da empresa para com seu próprio destino. A primeira propõe que essa está à mercê das forças econômicas e sociais predominantes e a segunda que acredita que os gestores têm controle sobre o futuro da firma através do planejamento e do controle.

Para os adeptos da primeira abordagem, o sucesso da organização depende da habilidade dos gestores de efetuar uma correta leitura do cenário. Para os seguidores do segundo ponto de vista, 0 êxito depende da qualidade das decisões do planejamento e controle gerencial. Para Figueiredo (1997, p. 42) "as empresas operam normalmente entre estes dois pontos de vista extremos".

Existem muitos elementos cuja gestão está fora do controle dos administradores da organização (Legislação, fatores demográficos, ambientais, sociais e culturais etc.) e outros que podem ser determinados por ela (Produtos e serviços prestados e suas características, estrutura de custos da empresa, recursos humanos etc.).

De acordo com Ward (1996, p. 33), a administração estratégica tem sido apresentada como um estilo de administração contínua, consistindo num processo interativo de análise, planejamento e controle. Ela também pressupõe que o processo de tomada de decisão estratégica requer o suporte de uma grande quantidade de informações variadas.

Ainda conforme 0 autor, se a contabilidade gerencial deve ser de valor para esse processo da administração estratégica, ela deve ser capaz de fornecer as informações requeridas dentro de um tempo apropriado ao nível do tomador de decisões " [...] o sistema de contabilidade gerencial estratégico deve ser estruturado para fornecer a apropriada informação financeira para suportar esses requerimentos específicos".(WARD, 1996, p.33). 
Padoveze (1996) comenta sobre a importância de uma entidade ter o apoio da Contabilidade gerencial na administração de seus negócios, pois segundo ele, se houver dentro dessa entidade pessoas que consigam traduzir conceitos contábeis em ações práticas, a Contabilidade será um instrumento para a administração.

Para Padoveze (2003) a controladoria estratégica é a atividade que, através do Sistema de Informação Contábil, abastece os responsáveis pelo Planejamento Estratégico da Companhia com informações tanto financeiras quanto não-financeiras, para apoiar o processo de análise, planejamento, implementação e controle da estratégia organizacional.

Em conformidade com Padoveze (2003) a controladoria estratégica deve se preocupar com aspectos relativos as mais variadas informações dos competidores, financeiras e não financeiras como: custos, rentabilidade dos produtos, informações sobre o processo de gestão de preços de vendas, capacidade produtiva dos concorrentes, satisfação dos clientes em relação à concorrência, motivos de negócios perdidos, grau de satisfação dos empregados etc.

O papel do profissional de contabilidade como estrategista organizacional fica evidente a partir do papel que a mesma possui na organização. Sua missão é assegurar o resultado planejado da empresa, através do processo de planejamento e controle dos resultados empresariais.

Para cumprir essa missão a Controladoria e seus responsáveis, possuem como instrumento fundamental o Sistema de Informação Contábil. Dentro de um sistema integrado de gestão empresarial verifica-se que o sistema contábil tem um papel primordial, por ser ao mesmo tempo a etapa final do fluxo de informações operacionais, mas também o sistema que direciona a parametrização da estruturação dos demais sistemas operacionais para, posteriormente, enviarem as informações necessárias ao planejamento e controle empresarial.

O Sistema de Informação Contábil deve ser estruturado para atender às necessidades informacionais de todo o processo de gestão da empresa. Desde o planejamento estratégico até 0 processo final de controle, passando pela programação, o sistema contábil deve estar apto para municiar e receber informações operacionais e financeiras.

Desta forma, a Controladoria Estratégica, quando desenvolvida adequadamente, melhora 0 nível do plano desenvolvido e influencia na capacidade da empresa responder ao ambiente em que atua.

\subsection{ESTRATÉGIA COMPETITIVA}

Segundo Mintzberg e Quinn (2001) não existe uma definição universalmente aceita para 0 termo estratégia, pois autores e gerentes o usam de maneira diferente. A própria palavra e os conceitos por ela evocados foram sofrendo modificações ao longo do tempo.

Segundo Motta (2000), no contexto organizacional a estratégia é a capacidade de se trabalhar, de forma contínua e sistemática, o ajustamento da organização às condições de um ambiente em mudança, tendo a visão de futuro da organização e a perpetuidade desta como meta.

Para Oliveira (1991) as estratégias têm como finalidade apresentar os caminhos a serem percorridos para que se possa alcançar os objetivos e superar os desafios estabelecidos. 0 conceito básico de estratégia está relacionado à ligação da empresa com seu ambiente e a melhor forma de desenvolver essa interação.

Para uma empresa estar preparada para as adversidades do mercado deve elaborar e definir bem uma estratégia, transformando-a em vantagem competitiva para si. Para Porter (1999) a essência da formulação da estratégia consiste em enfrentar a competição.

De acordo com 0 autor, estratégia competitiva é "A busca de uma posição competitiva favorável em uma indústria, a arena fundamental onde ocorre a concorrência. A estratégia competitiva 
visa estabelecer uma posição lucrativa e sustentável contra as forças que determinam a concorrência da indústria." (PORTER, 1989, p. 1).

Toda organização a partir do aprendizado com suas experiências passadas, da análise de seus pontos fortes e fracos e das oportunidades e ameaças que 0 ambiente impõe, faz uma avaliação desse cenário geral e traça seu caminho de ação para o futuro.

Segundo Porter (1989) a competição num determinado setor é determinada pela interação de cinco forças. São elas: ameaça de novos entrantes; poder de negociação dos fornecedores e dos consumidores; a ameaça de produtos substitutos e o grau de rivalidade entre as empresas do setor.

Frente a essas forças, o objetivo do estrategista empresarial é encontrar uma posição na qual a empresa seja capaz de melhor se defender contra essas forças ou de influenciá-las a seu favor. 0 conhecimento dessas forças, sobre como atuam e qual a pressão que estas exercem na indústria onde está inserida a empresa são os principais pontos sobre os quais são construídas as estratégias da organização. Essas cinco forças regem a competitividade e atratividade de um mercado qualquer. Para reagir a essas influências uma empresa deve aderir a uma das três estratégias genéricas: custo, diferenciação ou enfoque, sob pena de perder a identidade com o mercado.

Segundo Porter (1989) a estratégia competitiva a ser adotada pela empresa vai depender da estrutura industrial do setor em que ela atua e sua atratividade, além dos determinantes da posição competitiva relativa dela dentro da indústria. $O$ autor conceitua uma indústria como sendo um grupo de empresas que produzem produtos substitutos bastante próximos entre si.

Tendo em vista que nem todos os setores oferecem oportunidades iguais para 0 alcance de alta rentabilidade, a meta final da estratégia competitiva é lidar com os fatores determinantes da atratividade e, em termos ideais, modificá-las a seu favor.

Segundo Porter (1986) uma indústria é atrativa quando apresenta elevadas barreiras de entrada; quando fornecedores e clientes têm modestos poderes de barganha; quando os produtos e serviços substitutos são fracos e também quando a rivalidade entre os competidores se aproxima da estabilidade.

Assim, a atratividade a qual o autor se refere é resultado de um conjunto de forças que agem simultaneamente, criando assim circunstâncias favoráveis ou não para se realizar investimentos e competir numa determinada indústria. A estrutura industrial é relativamente estável, mas pode modificar-se com o passar do tempo à medida que essa se desenvolve.

Uma mudança estrutural altera o vigor global e relativo das forças competitivas, podendo, portanto, influenciar de uma forma positiva ou negativa a rentabilidade da indústria.

Tendo em vista que o objetivo da gestão da empresa é enfrentar essas forças da melhor forma possível, é preciso encontrar ações a fim de se criar uma boa posição dentro da indústria com o intuito de manter uma posição de sucesso, em longo prazo e de superar as concorrentes. Porter (1989) aborda ainda sobre as "Estratégias Genéricas" que, segundo ele, são três: Liderança no Custo Total; Diferenciação e Enfoque.

A busca pela liderança no custo exige a construção de instalações eficientes, escalas agressivas, perseguição contínua pela redução de custos, controle rígido das despesas, minimização dos investimentos em pesquisa e desenvolvimento, assistência ao cliente, força de vendas, entre outros aspectos.

Custo baixo em relação aos concorrentes torna-se o tema central de todas as ações desenvolvidas pela empresa, embora aspectos como qualidade, assistência e outras áreas não possam ser ignoradas.

$\mathrm{Na}$ estratégia de liderança no custo total são requeridos investimentos de capital em instalações eficientes, processos bem administrados, supervisão intensa, produtos projetados para facilitar a fabricação e sistema de distribuição com baixo custo.

A segunda estratégia, diferenciação, faz com que a empresa procure ser única no oferecimento de determinadas características oferecendo um pacote de valor superior ao da concorrência. Através 
desta estratégia, a empresa procura ser única em sua indústria selecionando alguns atributos que os compradores valorizam e posicionando-se de forma diferenciada para satisfazer estas necessidades. $\mathrm{Na}$ estratégia de diferenciação, ao contrário da abordagem do custo total, busca produzir ou prestar um serviço único na indústria e para tanto necessita de altos investimentos em pesquisa e desenvolvimento, desenvolvimento do produto e marketing, além de pessoas criativas e qualificadas.

Focar na estratégia de diferenciação não significa ignorar os custos, mas tratá-los de forma não prioritária. Na estratégia de diferenciação são requeridas grandes habilidades e investimento nas áreas de marketing, engenharia de produto, criatividade, pesquisa e desenvolvimento.

A terceira estratégia, o enfoque, diferencia-se das outras duas porque uma vez adotada esta estratégia, a empresa irá procurar atender a um segmento restrito dentro da indústria.

A empresa determina um grupo comprador com base em uma segmentação por linha de produtos, características geográficas, demográficas, etc. e prepara sua estratégia para atendê-lo, sendo que o enfoque pode ser em custo ou diferenciação. 0 enfoque no custo explora a diferença no comportamento em relação ao custo de algum segmento, enquanto que 0 enfoque em diferenciação procura atender necessidades especiais de alguma parcela de consumidores. Portanto, a diferença básica está no fato de que, enquanto as outras estratégias buscam alcançar seus objetivos no âmbito total da indústria, esta procura atingir seus objetivos em um segmento específico.

$\mathrm{Na}$ estratégia de enfoque é requerida uma reputação da empresa como líder em qualidade ou tecnologia, tradição na indústria ou combinação ímpar de habilidades trazidas de outros negócios. Cooperação com os canais de distribuição também é um fator importante para o sucesso desse tipo de estratégia.

\section{PROCEDIMENTOS METODOLÓGICOS}

A operadora de telefonia celular pesquisada surgiu da fusão de seis operadoras independentes que atuavam em regiões distintas do país. 0 grupo controlador da empresa, de origem mexicana, passou a comprar participações acionárias em empresas brasileiras do setor de telefonia móvel no ano 2000, criando uma empresa subsidiária para gerir suas operações no país.

A empresa possui atualmente mais de 14 milhões de clientes no Brasil atuando em 20 Estados e mais o Distrito Federal. Em nível nacional é a terceira colocada em número de clientes, sendo que em algumas regiões chega a ocupar a vice-liderança do mercado.

O método de estudo de caso é o mais pertinente para caracterização deste estudo, tendo em vista que, de acordo com Yin (2001) o método é adequado quando envolve o estudo profundo e exaustivo de um ou poucos objetos de maneira que se permita o seu amplo e detalhado conhecimento.

Em relação à natureza dos dados, a pesquisa pode ser classificada como qualitativa. Esse tipo de pesquisa, segundo Debus (1988) oferece técnicas especializadas para obter respostas a fundo acerca do que as pessoas pensam e quais são os seus sentimentos.

A pesquisa qualitativa não corresponde simplesmente às técnicas qualitativas para obtenção de respostas, mas sim a natureza da análise requerida para aplicá-la. Ela possui índole interpretativa e descritiva. De acordo com Debus (1988) é geralmente realizada em grupos pequenos de pessoas que geralmente não são selecionadas sobre a base da probabilidade.

A principal técnica utilizada para coletar os dados foi entrevista semi-estruturada, faz-se uso de um roteiro com tópicos sobre os assuntos a serem abordados, conforme os objetivos da entrevista. Este roteiro guia de forma mais flexível a interação entre o entrevistador e o entrevistado.

Esta técnica aumenta a participação do entrevistado na elaboração do conteúdo da investigação, permitindo-lhe seguir a linha de seu raciocínio e de sua vivência no foco principal colocado pelo entrevistador favorecendo uma interação dinâmica entre pesquisador e sujeito. A 
habilidade do pesquisador está em direcionar ações, não cerceando a inclusão de novos dados, sem deixar de exercer seleção criteriosa baseada na delimitação do problema (TRIVIÑOS, 1995).

Em relação à escolha da população que seria entrevistada o critério de escolha foi intencional. Para Triviños (1995) nesse caso, devem ser escolhidos sujeitos que sejam essenciais, segundo 0 ponto de vista do investigador, para o esclarecimento do assunto em foco, que sejam acessíveis ao contato e que sejam disponíveis para as entrevistas. Os indivíduos selecionados para colaborar com a pesquisa não foram selecionados mediante métodos probabilísticos, mas de acordo com a posição que ocupam na organização pesquisada tendo em vista que para participar do processo de planejamento estratégico se faz necessário ocupar determinados cargos na organização. Foram entrevistadas 05 pessoas ligadas à área executiva da empresa, incluindo-se entre estas o setor de Controladoria.

Houve o compromisso de manter 0 anonimato da empresa e resguardar a identidade dos respondentes.

\section{ANÁLISE DOS RESULTADOS}

A Controladoria apresenta papel fundamental na prestação de informações sobre 0 desempenho decorrido na empresa, sua comparação com os resultados projetados anteriormente, análise sobre as principais causas nas variações e relato sobre as ações desenvolvidas para corrigir tais desvios. Este departamento da empresa possui uma base de dados bastante detalhada e confiável sobre os aspectos operacionais e financeiros como dados a respeito de clientes e fornecedores. Entretanto, falta a esse órgão uma visão sobre aspectos tecnológicos, indispensáveis para os negócios, aspectos legais, tendo em vista a alta regulamentação do setor e aspectos externos do mercado como a concorrência que, conforme visto, é fator primordial na indústria de telefonia móvel. Essas informações são prestadas pelos departamentos de engenharia, jurídico e comercial respectivamente e se constitui em uma deficiência apresentada pelo órgão de controladoria, uma vez que sua função é municiar os gestores com informações relevantes para a empresa.

De posse das informações os executivos estabelecem cenários possíveis, alguns, considerando-se apenas a continuidade da situação atual e outros cuja suposição revela um exercício de criatividade dadas as mudanças cogitadas. A Controladoria, responsável pelo gerenciamento de alguns softwares de simulação empresarial, alimenta os sistemas com os dados e demonstra os resultados alcançados com as ações pretendidas para cada cenário. Esse exercício alimenta a busca por soluções criativas e inovadoras e, segundo os entrevistados, já ajudou a empresa a se antecipar e a preparar melhores defesas para algumas mudanças do mercado.

Em relação ao posicionamento da empresa de acordo com as estratégias genéricas de Porter (1986) após a análise ambiental interna e externa e das características da indústria em que estão inseridos, os gestores opinam que a organização deve se posicionar buscando a liderança em custo total, tendo em vista que as outras concorrentes que se apresentam no mercado procuram se posicionar por diferenciação. Uma delas apresenta o argumento da maior cobertura e a outra possui uma eficiente política de comunicação com o público jovem que faz com que seja bastante vinculada a este nicho, no entanto não deixa de atuar em outras frentes.

Segundo a análise dos gestores, nenhuma empresa de telefonia pode se posicionar de acordo com a abordagem do enfoque, pois escala é um fator primordial para conseguir cobrir os custos fixos que uma infra-estrutura dessas deve suportar.

$\mathrm{Na}$ interpretação dos executivos a empresa deve desenvolver ações que correspondam ao posicionamento desejado. Entre as ações desenvolvidas pela empresa destacam-se as compras em grandes volumes para conseguir bons descontos com fabricantes e repassar os equipamentos aos clientes por um preço mais atrativo. Segundo os gestores, o preço do aparelho ainda é determinante no 
Brasil para a escolha da operadora, pois o cliente muitas vezes deseja o objeto e não o serviço. Desta forma, são comuns promoções com preços agressivos e prazos elásticos. 0 retorno desse investimento se dá através da cobrança das tarifas.

Baseado no argumento anterior, de que os clientes buscam o equipamento e não o serviço, 0 preço das tarifas da operadora não acompanha a orientação da liderança em custo. A empresa possui um porttólio de planos cujos preços variam bastante, vencendo os concorrentes em alguns casos e perdendo em outros.

No posicionamento por custos a eficiência dos controles internos se torna primordial para o sucesso da estratégia, uma vez que a estrutura da empresa deve estar adequada as suas pretensões de prestar um serviço ou vender um produto adequado ao menor preço possível dentre as concorrentes. Custos salariais, de engenharia, propaganda, entre outros mencionados anteriormente são cuidadosamente analisados para que não aconteçam redundâncias, superposições ou gastos desnecessários.

Através da metodologia de Porter (1986) para análise da indústria ficam expostas as principais características estruturais e os fatores críticos desse setor, bem como a sua complexidade e influência dos fatores na sua atratividade. Para as "cinco forças" de Porter (1986) as respostas dos executivos permitiram identificar os seguintes aspectos no mercado em que atuam, sumarizados a seguir.

a) Risco de entrada de novos competidores: para a indústria em questão, esse fator não é tão importante uma vez que na maioria dos estados do país já estão instaladas três ou até quatro operadoras, inibindo uma possível entrada de um novo concorrente. Além disso, a alta regulamentação do setor evita que as empresas sejam surpreendidas por concorrentes inesperados, dando-lhes tempo de se preparar adequadamente para a competição.

A unidade de Controladoria não desempenha um papel relevante na detecção dos riscos associados a esse fator de competitividade da indústria tendo em vista que as informações são muitas vezes dispersa, pelo sigilo que permeia aquisições de empresas por outras ou da tentativa de empresas de entrar em áreas de outras. Tais informações são "captadas" informalmente, através de contatos dos executivos com outros de empresas concorrentes, parceiros, fornecedores, funcionários, imprensa ou até mesmo com clientes. Não existe uma sistematização para a coleta e armazenamento desse tipo de informação. Dessa forma, segundos relatos dos gestores, aconteceram fatos que inicialmente passaram despercebidos, mas depois de algum tempo vieram a se tornar relevantes. Caso houvesse um sistema para tratamento dessas informações talvez fosse mais fácil se antecipar a essas mudanças.

b) Ameaça de produtos substitutos: para esse fator, o setor como um todo, aproveita-se do fato dele mesmo se configurar como um substituto para serviços de outras indústrias, como é o caso da área de telefonia fixa, rastreamento de mercadorias e pessoas, comunicação de dados, entretenimento, jogos eletrônicos, entre outros. A fonte maior de receitas das empresas, serviços de voz, vem dividindo espaço cada vez maior com receitas provenientes de outras aplicações possíveis para a infra-estrutura instalada, tornando a indústria uma propulsora de novos negócios e novas formas de gerar receitas com serviços afins.

Entretanto, um fator foi levantado por um dos executivos que é o crescimento da utilização da infra-estrutura de Internet para o tráfego de voz. Tal ameaça hoje já é perceptível na telefonia fixa e já começa a preocupar os executivos de telefonia móvel tendo em vista que para ligações interurbanas, internacionais ou até mesmo locais, os custos de utilização dessas novas formas de comunicação já superam com vantagem os custos dos serviços oferecidos pelas empresas do setor.

A controladoria apresenta-se com condições de desempenhar o monitoramento de fatores ligados a esse tópico da análise ambiental, pois estas mudanças na maioria das vezes são conhecidas pelo pessoal de áreas mais técnicas como engenharia ou por áreas como a comercial, que possuem um contato maior com o mercado. Entretanto, falta uma interação maior da unidade com essas áreas da empresa segundo relatos apresentados por alguns respondentes. 
c) Rivalidade entre os concorrentes: esta se constitui na maior ameaça que a empresa enfrenta atualmente, assim como todas as empresas que compõem o setor. Com exceção de apenas uma empresa do setor, todas as outras já possuem um padrão tecnológico igual, o GSM. Desta forma, a mudança para o cliente é muito fácil e não acarreta maiores transtornos. Mesmo sem cancelar um plano com a operadora, o cliente que se divide entre duas prestadoras de serviço acaba deixando menos recursos em cada uma delas do que se dedicasse toda sua atenção a apenas uma delas. Esse comportamento do consumidor faz também com que sejam freqüentes as tentativas de cancelamento, muitas vezes abrandadas apenas com descontos generosos que acabam corroendo a rentabilidade da empresa com aquele consumidor.

Outro fato que agrava o nível de competitividade no setor é a possibilidade que o cliente terá, a partir de 2006, de migrar de uma operadora para outra mantendo consigo o número original, ou seja, 0 número passará a ser do cliente e não do prestador de serviço. Com isso, a fidelidade conquistada em virtude do critério de tempo de permanência com a mesma linha, que atinge principalmente as operadoras que se instalaram primeiro, deixa de existir.

Embora apresente poucos concorrentes, este sem dúvida, na opinião dos gestores é o fator que mais afeta a atratividade do setor em questão, pois pode levar os integrantes do mercado a uma guerra de preços.

Outro fato que contribui para o acirramento da competição entre os atores desse setor são os enormes custos de implantação de suas redes que precisam ser amortizados. De fato, em telecomunicações dependendo do perfil de uso do cliente, praticamente não existe custo variável. Por exemplo, clientes que ligam para números de sua própria operadora praticamente não representam custos para as mesmas. As barreiras de saída do setor são muito altas, pois se trata de um negócio bastante específico.

Desta forma, o grau de rivalidade é importante para a indústria constituindo-se em sua principal força para diminuir sua atratividade, mas ainda não inviabiliza as margens desejadas pelas empresas. Em um futuro com taxas de crescimento menor ou até mesmo com estabilização no número de novos clientes, esse fator tende a se potencializar.

A Controladoria apresenta informações sobre os concorrentes, mas não existe na empresa um sistema de inteligência competitiva que supra permanentemente a mesma com dados sobre fatores concorrenciais.

d) Poder de negociação dos fornecedores: essa força possui potencialmente o poder de mudar os planos das operadoras, mas, acredita-se que em virtude da pequena quantidade de empresas compradoras e da característica de venda do equipamento, muitas vezes subsidiada pela operadora, ela não tem sido exercida pelas empresas fornecedoras de equipamentos, quer sejam para uso das empresas ou repasse para clientes.

Os fornecedores possuem como maior canal de distribuição as próprias operadoras, dessa forma não se sentem motivados a promoverem ações que possam desagradar esses importantes clientes e parceiros.

Além disso, com o surgimento de novas empresas provedoras de equipamentos a posição do mercado de bens para as empresas de telefonia móvel está se tornando mais competitiva, resultando em maiores vantagens para as empresas operadoras de telefonia móvel no Brasil e no mundo.

A unidade administrativa responsável pela Controladoria devido a seu estreito relacionamento com o setor de compras, financeiro e contábil, possui registros, índices e análises sobre esse aspecto, suprindo adequadamente os gestores com informações sobre esse fator de mercado. Além disso, 0 pequeno número de fornecedores mais importantes, como aqueles de infra-estrutura, permite um conhecimento detalhado sobre estes, bem como oferece possibilidades de estabelecer padrões de desempenho entre eles em aspectos como preço, qualidade dos serviços, suporte tecnológico, etc.

e) Poder de negociação dos compradores: os consumidores, tendo em vista a condição de pulverização do mercado não se apresentam como potenciais ameaças, no sentido preconizado pela 
metodologia de Porter (1986), pois mesmo aqueles que possuem um alto perfil de consumo de serviços são irrelevantes se considerados isoladamente. A empresa não depende especificamente de nenhum consumidor ou grupo de consumidores. Além disso, os consumidores não possuem poder de mobilização para atuar conjuntamente na defesa de seus interesses. Entretanto, um fato que deve ser considerado em relação aos consumidores é a pouca fidelidade deles em relação às operadoras conforme relatado no item relativo à concorrência.

A empresa possui dados sobre seus clientes e os utiliza para traçar ações diferenciadas para cada segmento que se deseja trabalhar. Esse conhecimento, aliado aos fatores expostos anteriormente neste tópico, confere à empresa uma dose adequada sobre esse item competitivo minimizando o seu risco de interferir na competitividade da indústria.

De forma geral, os gestores da organização em questão sentem que ainda são capazes de desenvolver planos para defender-se das forças competitivas que afetam negativamente os interesses desta e promover manobras estratégicas que melhorem a posição da empresa.

Portanto, em acordo com a metodologia das cinco forças, o entendimento que os gestores possuem da indústria em que atuam é que esta é atrativa, sendo a principal ameaça o grau de rivalidade entre os integrantes da mesma.

Para a determinação do posicionamento da empresa as pessoas responsáveis por sua estratégia tentam construir mecanismos de defesa contra as cinco forças competitivas ou descobrir posições no setor no qual essas forças são mais brandas.

\section{CONCLUSÃO}

O resultado da pesquisa evidencia a importância da Controladoria para o planejamento estratégico da empresa na medida em que coleta, trata e fornece informações que são úteis ao plano de longo prazo da companhia, auxiliando na determinação da estratégia competitiva da empresa. Entretanto, de acordo com 0 estudo de caso, tais informações poderiam ser complementadas. Conforme exposto, fatores como risco de entrada de novos competidores e ameaça de produtos substitutos não são monitorados e a rivalidade entre as empresas do setor possui um monitoramento inferior ao que seria necessário para as necessidades da empresa.

Entretanto, mesmo mostrando-se útil aos objetivos da empresa em questão, a Controladoria não apresenta informações completas para áreas, sendo que estas são chaves para 0 desenvolvimento e sobrevivência da organização, pois afetam sua situação regulatória, tecnológica e principalmente de mercado. Tendo em vista o objetivo da empresa de se posicionar baseado em custo, é de fundamental importância possuir todas as informações sobre os elementos que a levam a ser percebida pelo mercado como detentora de tal posição.

Desta forma, observa-se que a atuação da unidade de controladoria possui um papel relevante para a elaboração do plano estratégico dessa empresa, o que provavelmente tem reflexos em sua competitividade na medida em que a partir do maior conhecimento de sua atuação interna e externa pode fazer escolhas estratégicas para melhor se posicionar no mercado. Entretanto, tendo em vista 0 tipo de estudo ora desenvolvido, estudo de caso, convém destacar que, em função de suas características exploratórias, além de sua amostra intencional e não-probabilística, esse trabalho possui restrições quanto à generalização de seus resultados. 


\section{REFERÊNCIAS}

BRASIL. Ministério das Comunicações. Ajuda: Glossário. Disponível em < http://www.anatel.gov.br/AJUDA/GLOSSARIO>. Acesso em: 20 mai. 2005a.

Ministério das Comunicações. Telecomunicações: Linha do Tempo. Disponível em $<$ <ttp://www.mc.gov.br/historico/telefonia/default.htm>. Acesso em: 20 mai. 2005b.

Ministério das Comunicações. Paste - Perspectivas para ampliação e modernização do setor de Telecomunicações. Brasília, 2000.

Ministério do Planejamento (1981/1993). Relatório anual da Secretaria Especial de Controle das Estatais SEST. Brasília, 1994.

BIONDI, Aloysio. 0 Brasil Privatizado: Um Balanço do Desmonte do Estado. São Paulo: Fundação Perseu Abramo, 1999.

CATELLI, Armando (Coordenador). Controladoria: uma abordagem da gestão econômica - GECON $2^{a}$ ed. - São Paulo: Atlas, 2001.

DAY, G. S. Estratégia voltada para o mercado: processos para criação de valor dirigidos ao cliente. Rio de Janeiro: Record, 1990.

DEBUS, Mary. (Org.). Manual para excelência em la investigación mediante grupos focales. Pennsylvania: University of Pennsylvania/ Applied Communications Technology, Needham Porter Novelli, 1988.

DRUCKER, P. F. Administrando em tempos de grandes mudanças. São Paulo: Pioneira, 1999. A prática da administração de empresas. São Paulo: Pioneira, 1998.

FOSS, N. J.Research in strategy, economics and Michael Porter. Journal of Management Studies, v.33, 1996.

GODOY, Arilda S. Introdução à pesquisa qualitativa e suas possibilidades. RAE - Revista de Administração de Empresas, v. 35, n. 2, p. 57-63, Mar/Abr, 1995.

GOODE, W. J., HATT, P. K. - Métodos em Pesquisa Social. 3ㄹạed., São Paulo: Nacional, 1969.

KIM, L.; LIM, Y. Environment, generic strategies and performance in a rapidly changing country : a taxonomic approach. Academy of Management Journal, v.31, p.802-827, 1988.

KOTLER, P. Administração de marketing: análise, planejamento, implementação e controle. 4ª ed. São Paulo: Atlas, 1994.

LEAL, Sayonara de A.G. O Sistema de Telecomunicações no Brasil: As Alterações no Modelo de Monopólio Público de Sarney a Fernando Henrique Cardoso (FHC). Disponível em <http://www.eptic.he.com.br/revista/rv1_11.htm>. Acesso em: 15 mai. 2005. 
MARTINS, Eliseu. O papel do contador estratégico do futuro - controladoria e contabilidade estratégicas. 1 Simpósio Nacional IOB de Contabilidade. São Paulo: 1998.

MINTZBERG, Henry. Generic strategies: toward a comprehensive framework. Advances in strategic management. v.5, Greenwich, Conn.: Jay Press, 1988.

MINTZBERG, Henry, QUINN, James Brian. 0 processo de estratégia. 3. ed., Porto Alegre: Bookman, 2001.

MOTTA, Paulo Roberto. Transformação Organizacional: a teoria e a prática de inovar. Rio de Janeiro: Qualitymark, 2000.

OLIVEIRA, D. P. R. Estratégia empresarial: uma abordagem empreendedora. 2. ed., São Paulo: Atlas, 1991.

Planejamento Estratégico: conceitos, metodologia, e práticas. São Paulo: Atlas, 1998.

PADOVEZE, Clóvis Luís. Contabilidade gerencial: um enfoque em sistema de informação contábil. São Paulo: Atlas, 1996.

Controladoria Estratégica e Operacional: conceitos, estrutura, aplicação. São Paulo:

Pioneira Thomson Learning, 2003.

PESSINI, José Eduardo. A indústria brasileira de telecomunicações: uma tentativa de interpretação das mudanças recentes. Campinas: UNICAMP, Instituto de Economia, 1986.

PORTER, Michael L. Estratégia Competitiva: Técnicas para análise de Indústrias e da Concorrência. Rio de Janeiro: Campus, 1986,.

Campus, 1989.

Vantagem Competitiva: criando e sustentando um desempenho superior. Rio de Janeiro:

Competição: estratégias competitivas essenciais. Rio de Janeiro: Campus, 1999.

RICHARDSON, Roberto (Org). Pesquisa Social 3ª Ed.. São Paulo: Atlas, 1999.

SIQUEIRA, Ethevaldo. Telecomunicações: privatização ou caos. São Paulo: TelePress, 1993.

TRIVINOS, A N. S. Introdução à pesquisa em ciências sociais: a pesquisa qualitativa em educação. São Paulo: Atlas,1995.

VIANNA, Gaspar. Privatização das telecomunicações. Rio de Janeiro: Notrya, 1993.

WAJNBERG, Salomão. A Indústria de equipamentos de telecomunicações no Brasil da segunda metade da década de 70 até hoje. In BARROS, Henry Lins (org.). História geral das

Telecomunicações no Brasil. Rio de Janeiro, Associação Brasileira de Telecomunicações TELECOM, 1989.

WARD, Keith. Strategic management accounting. Oxford: Butterworth-Heinemann, 1996.

YIN, Robert K. Estudo de Caso: planejamento e métodos. Porto Alegre: Bookman, 2001. 


\section{CONTROLLING AS A SUPPORTTOOL FOR COMPETITIVE STRATEGIES: CASE STUDY IN A MOBILE TELEPHONE COMPANY}

This article aims to investigate the paper of the Managemental Accounting department of a Brazilian Mobile Phone Company in the support to the competitive strategies. This research is important because this sector is of most dymanic and import of Brazilian and worldwide, thus possessing, potential to spread new practical of management that if they show utility in the resolution of the enterprise problems. A research was carried through, involving on interviews with controllers of the Managemental Accounting sector and executives to the organization. The results had evidenced that the information of this department make possible the knowledge of the market, of form to face the competition. The agreement that the managers possess of this industry is its attractiveness. The main threat the competitiveness of the organization in the market is the degree of rivalry of the competitors.

Key Words: Mobile Telephony. Managemental Accounting. Competitiveness.

Data de Submissão: janeiro de 2007

Data de Aceite: maio de 2007 